\title{
Platelet-Derived Growth Factors Stimulate Proliferation and Extracellular Matrix Synthesis of Pancreatic Stellate Cells: Implications in Pathogenesis of Pancreas Fibrosis
}

\author{
Thomas Luttenberger, Alexandra Schmid-Kotsas, Andre Menke, Marco Siech, \\ Hans Beger, Guido Adler, Adolf Grünert, and Max G. Bachem \\ Department of Clinical Chemistry and Pathobiochemistry (TL, AS-K, AG, MGB), Department of Medicine I (AM, GA), \\ and Department of Surgery (MS, HB), University Hospital UIm, UIm, Germany
}

\begin{abstract}
SUMMARY: At present, the cell-cell interactions and molecular mechanisms of pancreas fibrogenesis are largely unknown. The purpose of this study was to investigate paracrine stimulatory loops between platelets and pancreatic stellate cells (PSC). Human PSC were obtained by outgrowth from fibrotic human pancreas. Native platelet lysate (nPL) and transiently acidified platelet lysate (aPL) were added to cultured PSC (passage 4 to 7 ) in the absence of serum. The synthesis of collagen types I and III and c-fibronectin (cFN) was demonstrated on protein (immunofluorescence and quantitative immunoassay) and mRNA (Northern blot) level. Using sections of human pancreas with acute pancreatitis, platelet aggregates in capillaries were demonstrated by transmission electron microscopy. $\mathrm{nPL}$, and to an even greater extent aPL, significantly increased the synthesis of collagen types I and III and of c-FN (120 $\mu \mathrm{l} / \mathrm{ml}$ aPL increased collagen type I concentration in PSC supernatants by $1.99 \pm 0.17$ times and c-FN of $2.49 \pm 0.28$ times, mean $\pm \mathrm{SD}, n=3$ ). $\mathrm{nPL}$ and $\mathrm{aPL}$ also significantly stimulated cell proliferation (increased bromodeoxyuridine (BrdU) incorporation by $6.4 \pm 0.78$ times and $10 \pm 0.29$ times, respectively). By preincubating aPL with transforming growth factor $\beta$ (TGF $\beta$ )- and platelet-derived growth factor (PDGF)-neutralizing antibodies and the TGF $\beta$-latency associated peptide, respectively, TGF $\beta 1$ was identified as the main mediator stimulating matrix synthesis and PDGF as the responsible mitogen. Our data demonstrate that platelets contain fibrogenic mediators that stimulate proliferation (PDGF) and matrix synthesis (TGF $\beta 1$ ) of cultured PSC. We suggest that platelets and PSC cooperate in the development of pancreas fibrosis. (Lab Invest 2000, 80:47-55).
\end{abstract}

\begin{abstract}
Chronic pancreatitis is characterized by the pres$C$ ence of chronic inflammatory lesions, by the destruction of exocrine parenchyma, and by fibrosis (Kennedy et al, 1987; Uscanga et al, 1987; Sarles et al, 1990; Di Magno et al, 1993). At present, the pathobiochemical and molecular mechanisms resulting in pancreas fibrosis are controversial and largely unknown. Activation of fibroblasts and "fibroblast-like" cells was reported to be a common observation in acute and chronic pancreatitis (Elsässer et al, 1986, 1989; Uscanga et al, 1987). It was suggested that periacinar fibroblast-like cells might play a role in fibrogenesis by synthesizing significant amounts of extracellular matrix, in particular collagens (Gress et al 1994; Kato et al, 1996; Saotome et al, 1997). Recently the presence of retinoid-containing pancreatic stellate cells (PSC) was demonstrated in rats and humans (Apte et al, 1998; Bachem et al, 1998). We have cultured and
\end{abstract}

Received September 14, 1999

Grant support from Bausteinförderung University of Ulm (P.347 to MGB) and Deutsche Forschungsgemeinschaft (SFB 518, Project A7 to MGB).

Address reprint requests to: Priv. Doz. Dr. Dr. M.G. Bachem, Universität Ulm-Klinikum-Institut für Klinische Chemie, Bereichslabor Michelsberg, 89070 ULM, Germany. Fax 49731502 6719; E-mail max.bachem@ medizin.uni-ulm.de characterized the cells and have shown that PSC synthesize the same extracellular matrix components that are found in pancreas fibrosis, namely collagen types I and III and fibronectin (Bachem et al, 1998). Because PSC are similar in their morphology and biochemistry to hepatic stellate cells (Bachem et al, 1998), PSC are suspected to play the same role in pancreas fibrogenesis as hepatic stellate cells do in liver fibrosis.

Elsässer and coworkers (Elsässer et al, 1986, 1989) have shown that in the cerulein-induced pancreatitis model, proliferation of acinar and centroacinar cells is associated with an accelerated mitotic activity of fibroblasts that is followed by a stimulated synthesis and deposition of collagen. During regeneration from cerulein-induced pancreatitis, the expression of transforming growth factor $\beta$ (TGF $\beta$ ) is enhanced in acinar and "stromal cells" of rat pancreas (Gress et al, 1994). Interestingly, TGF $\beta$-protein increase was detected 24 hours earlier as the increase in TGF $\beta 1$ mRNA expression (Gress et al, 1994), suggesting that platelets might be the source of the early $\operatorname{TGF} \beta$ release in cerulein-induced pancreatitis. Following acinar cell injury, platelets aggregate in areas of inflammation (Bockman, 1988; Bockman et al, 1986). Platelets represent the major storage site for TGF $\beta$ (Assoian et al, 
1983, 1986) and contain several other growth factors, such as platelet-derived growth factor (PDGF) (Antoniades et al, 1979; Heldin et al, 1981) and epidermal growth factor/transforming growth factor $\alpha$ (Oka and Orth, 1983), which all represent fibrogenic and/or mitogenic mediators. In this study we investigated the effect of platelet lysate on human PSC in cellproliferation and extracellular matrix synthesis. To define the role of activated TGF $\beta 1$, we compared the effects of native platelet lysates (nPL) with those of transiently acidified platelet lysates (aPL). During ultrasonification of platelets, TGF $\beta 1$ is released in a latent form from alpha-granules and can be activated by transient incubation at $\mathrm{pH} 2$ (Miyazono et al, 1988). Transiently acidified platelet lysate increased the synthesis of c-fibronectin (cFN) and collagen types I and III in cultured human PSC and enhanced their proliferation. Using neutralizing antibodies to TGF $\beta 1$ and PDGF, we identified TGF $\beta 1$ as the main stimulator of matrix synthesis and PDGF as the mitogen responsible for stimulating PSC proliferation.

\section{Results}

\section{Demonstration of Platelet Aggregates in Acute Pancreatitis}

Figure 1 shows a capillary lumen within pancreatic tissue from a female patient suffering from acute biliary pancreatitis. Within the capillary lumen, an aggregation of platelets is found. The majority of platelets contain typical electron-dense granules, others are already degranulated.

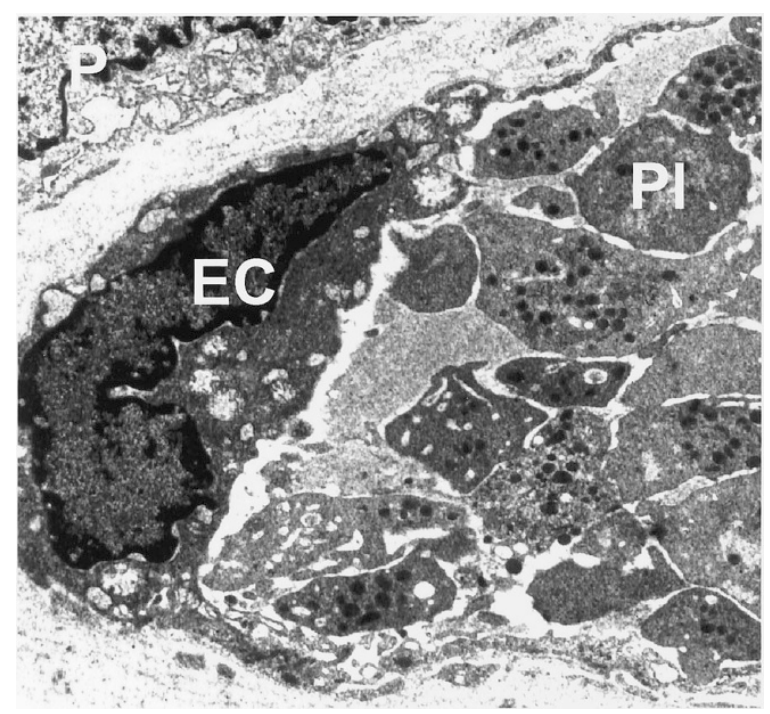

Figure 1.

Electron micrograph of a capillary lumen containing an aggregation of platelets. Pancreatic tissue was surgically resected from a woman with acute biliary pancreatitis. The tissue was fixed for 1 hour in a mixture of $2.5 \%$ glutaraldehyde and $2.5 \%$ formaldehyde. Standard procedures were used for dehydration and embedding. Ultrathin sections were stained with uranyl acetate and lead citrate, and examined using a transmission electron microscopy. PI, platelet; $E C$, endothelial cell; $P$, pericyte. Original magnification $\times 4500$.

\section{Effect of Platelet Lysate on Pancreatic Stellate Cell Proliferation}

To investigate the effect of platelet lysate on proliferation of cultured PSC, BrdU-incorporation was measured during a labeling period of 16 hours. Optimal BrdU concentration and labeling time was determined in earlier experiments. Incorporated BrdU was immunostained (Fig. 2) and measured by time-resolved fluorescence-immunoassay (Fig. 3b). DNA was measured 6 days after addition of PL to cultured PSC (Fig. 3a). As shown in Figure 2, addition of platelet lysate to PSC cultured in the presence of $0.5 \%$ fetal calf serum resulted in an increased number of stained cell nuclei. In control PSC (Fig. 2A), a fraction of 0.09 incorporated BrdU; in the presence of $10 \%$ fetal calf serum (Fig. 2B) a fraction of 0.68 was stained; addition of $120 \mu \mathrm{laPL}$ (Fig. $2 \mathrm{~F}$ ) resulted in an increased BrdU incorporation to a fraction of 0.98. The effects of aPL (Fig. 2, D and F) were more pronounced than $\mathrm{nPL}$ (Fig. 2, C and E).

By 144 hours after addition of PL, DNA content per culture increased from $0.68 \mu \mathrm{g} /$ well (control) to 1.13 $\mu \mathrm{g} /$ well in cultures receiving $120 \mu \mathrm{lnPL}$, and to 1.97 $\mu \mathrm{g} /$ well in cultures receiving $120 \mu \mathrm{l}$ aPL (Fig. 3a). Furthermore, BrdU immunoassay demonstrated that

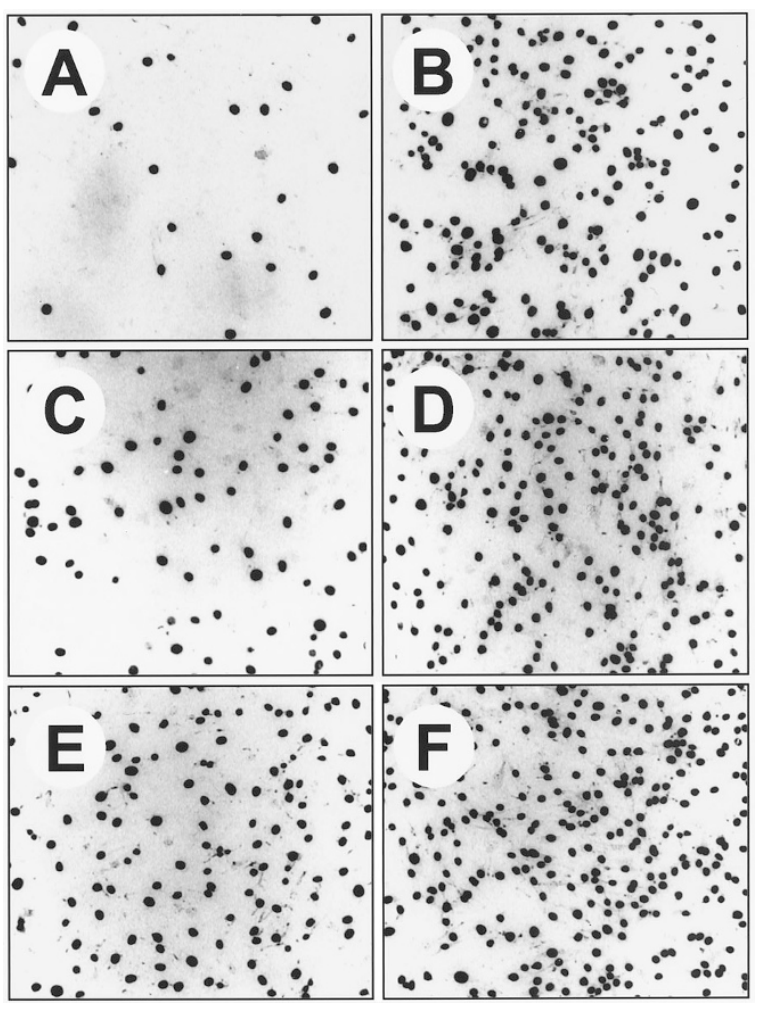

Figure 2.

Effect of platelet lysate on bromodeoxyuridine (BrdU) incorporation (immunoperoxidase staining). Human pancreatic stellate cells (PSC) were cultured in the presence of $0.5 \%$ fetal calf serum (FCS). Four hours after addition of platelet lysates (30 and $120 \mu \mathrm{l} / \mathrm{ml}$ medium) BrdU (final concentration $10^{-5} \mathrm{M}$ ) was added. Cultures were stopped 16 hours later. BrdU incorporation was visualized by immunoperoxidase staining using diaminobenzidine (DAB). (A) Control culture receiving $0.5 \%$ FCS; (B) PSC receiving 10\% FCS; (C) addition of $30 \mu \mathrm{l} / \mathrm{ml}$ native platelet lysate $(\mathrm{nPL})$; (D) addition of $30 \mu \mathrm{l} / \mathrm{ml}$ transiently acidified platelet lysate (aPL); (E) addition of $120 \mu \mathrm{l} / \mathrm{ml} \mathrm{nPL;} \mathrm{(F)} \mathrm{addition} \mathrm{of} 120$ $\mu \mathrm{l} / \mathrm{ml} \mathrm{aPL}$. 

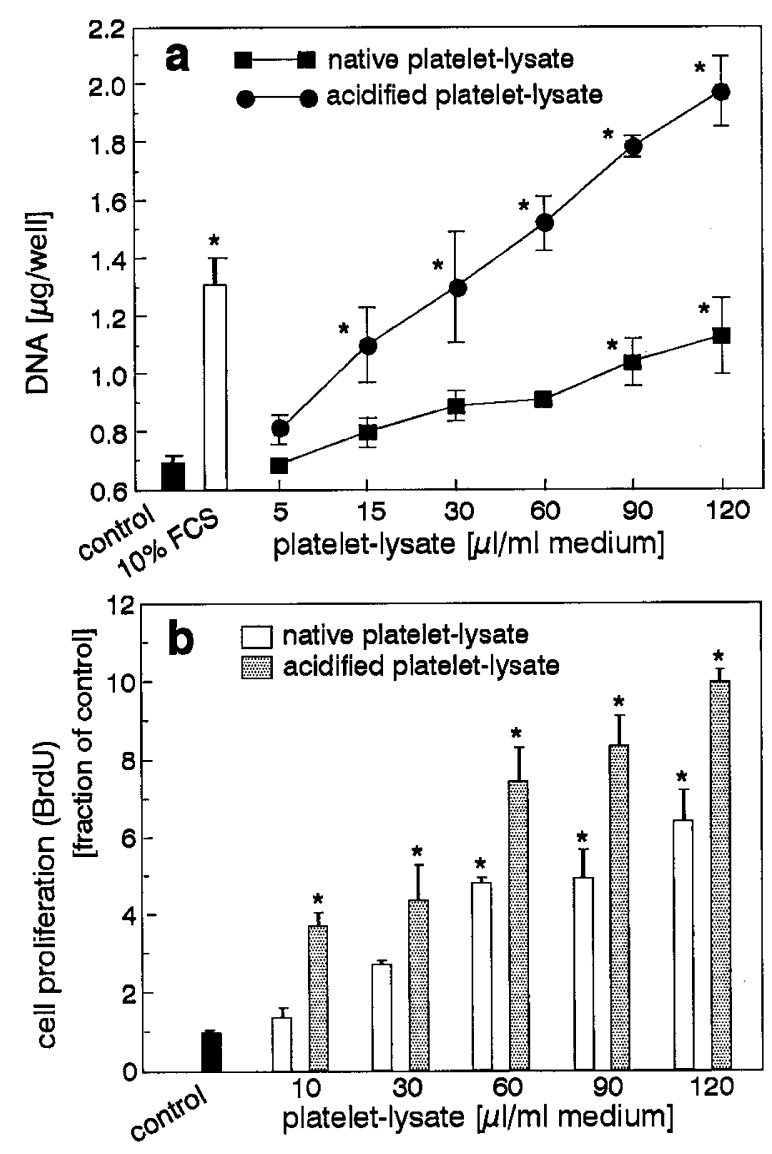

Figure 3.

Effect of platelet lysate on proliferation of cultured human PSC. (a) Measurement of DNA. Human PSC were seeded at $10^{5} \mathrm{cell} / \mathrm{s} / \mathrm{cm}^{2}$ and cultured in the presence of $0.5 \%$ FCS. Seventy-two hours after addition of native and transiently acidified platelet lysates $(5,15,30,60,90$, and $120 \mu \mathrm{l} / \mathrm{ml}$ medium) the medium was changed and cell cultures were stimulated for further 72 hours. Cultures were stopped and DNA was measured by fluorometry using bisbenzimide. Mean values \pm SD of three independent experiments, each with $n=3$. (b) Measurement of BrdU incorporation. Human PSC were cultured in the presence of $0.5 \%$ FCS. Four hours after addition of nPL and aPL (10, 30, 60,90 , and $120 \mu \mathrm{l} / \mathrm{ml}$ medium) BrdU (final concentration $10^{-5} \mathrm{M}$ ) was added. Cultures were stopped 16 hours later. BrdU incorporation was measured quantitatively as described in the Methods section. Mean values \pm SD of three independent experiments, each with $n=3$.

$\mathrm{nPL}$, and even more notably aPL, dose-dependently stimulated PSC proliferation (Fig. 3b). nPL (120 $\mu \mathrm{l} / \mathrm{ml})$ enhanced BrdU incorporation 6.4-fold and aPL (120 $\mu \mathrm{l} / \mathrm{ml}$ ) enhanced BrdU incorporation 10-fold (Fig. 3b) over control levels (Fig. 3b).

\section{Effect of Platelet Lysate on the Synthesis of Collagen and Fibronectin by Cultured Pancreatic Stellate Cells}

To demonstrate the effects of PL on cell-associated collagens and fibronectin, cultured human PSC were incubated for 36 hours with $\mathrm{nPL}$ and aPL, respectively. Thereafter, cultures were fixed and immunostaining was performed. As shown in Figure 4, intensive staining patterns of collagen type I (Fig. 4, C and E) and fibronectin (Fig. 4, D and F) were observed in cultures receiving $120 \mu \mathrm{l} / \mathrm{ml} \mathrm{nPL} \mathrm{(Fig.} \mathrm{4,} \mathrm{C} \mathrm{and} \mathrm{D)} \mathrm{and} \mathrm{aPL} \mathrm{(Fig.}$ 4, $\mathrm{E}$ and F). Collagen type I immunoreaction was detected predominantly intracellularly with the highest intensity in the perinuclear region. PSC stimulated with PL appeared larger (Fig. 4, C and E) compared with control cells (Fig. $4 \mathrm{~A}$ ) receiving $0.5 \%$ fetal calf serum. Fibronectin (Figs. 4, B, D, and F) was located intracellularly and in extracellular fibrillar structures that varied in density. As shown in Figure 5, the steady state levels of collagen type I-mRNA and fibronectin-mRNA were only slightly increased by $\mathrm{nPL}$ and $\mathrm{aPL}$ in secondary cultured human PSC.

The stimulating effects of PL on the synthesis of extracellular matrix were also demonstrated by measuring the concentration of procollagen-peptides I and III and cFN in cell culture supernatants. As shown in Figure $6 \mathrm{a}$, addition of PL to cultured PSC caused a dose-dependent increase in cFN concentration. Fibronectin concentrations were expressed per $\mu \mathrm{g}$ DNA to exclude the effect of PL on cell number. At all concentrations tested, aPL stimulated cFN synthesis to a higher degree than $\mathrm{nPL}$ (an increase of $1.6 \pm 0.3$ versus $2.49 \pm 0.28$ (Fig. 6a). To increase the collagen proline hydroxylation, ascorbic acid $(100 \mu \mathrm{g} / \mathrm{ml}$ medium) was added to the culture medium in experiments demonstrating the effects of PL on collagen synthesis. Calculations of procollagen-I and -IIIpeptide concentrations on their corresponding DNA showed that $\mathrm{aPL}$, but not $\mathrm{nPL}$, increased collagen synthesis significantly (Fig. 6, b and c).

To identify the fibrogenic mediators that stimulate proliferation and matrix synthesis, aPL was preincubated for 30 minutes with the TGF $\beta$-latency associated peptide (LAP) and neutralizing antibodies to PDGF and TGF $\beta 1$, respectively, before the lysate was added to cultured PSC. Neutralizing anti-PDGF(AB) significantly reduced the stimulatory effect of $P L$ on BrdU-incorporation (Fig. 7a), whereas anti-TGF $\beta 1$ and LAP significantly reduced the cFN synthesis stimulating activity of PL (Fig. 7b).

\section{Discussion}

In this study we demonstrate for the first time that native and - in particular - transiently acidified platelet lysate increased the synthesis of cFN and collagen types I and III in cultured human PSC. In addition, platelet lysate enhanced proliferation of these cells. By preincubating the platelet lysates with neutralizing antibodies to TGF $\beta 1$ and PDGF, we identified TGF $\beta 1$ as the main mediator matrix synthesis-stimulating and PDGF as the most important mitogen in PL.

The role of platelets as a source of an early TGF $\beta$ release in acute pancreatitis was suggested by an earlier study by our group demonstrating that the TGF- $\beta$ protein increased earlier than TGF $\beta 1$ mRNA in pancreas tissue of rats with cerulein pancreatitis (Gress et al, 1994). In this model, TGF $\beta 1$ gene expression paralleled collagen type I gene expression and after the initial release from platelets, TGF $\beta 1$ was produced by inflammatory cells, stromal cells, and acinar cells (Gress et al, 1994). Furthermore, recently obtained data suggest that initially released TGF $\beta 1$ could induce its own de novo synthesis in PSC, 

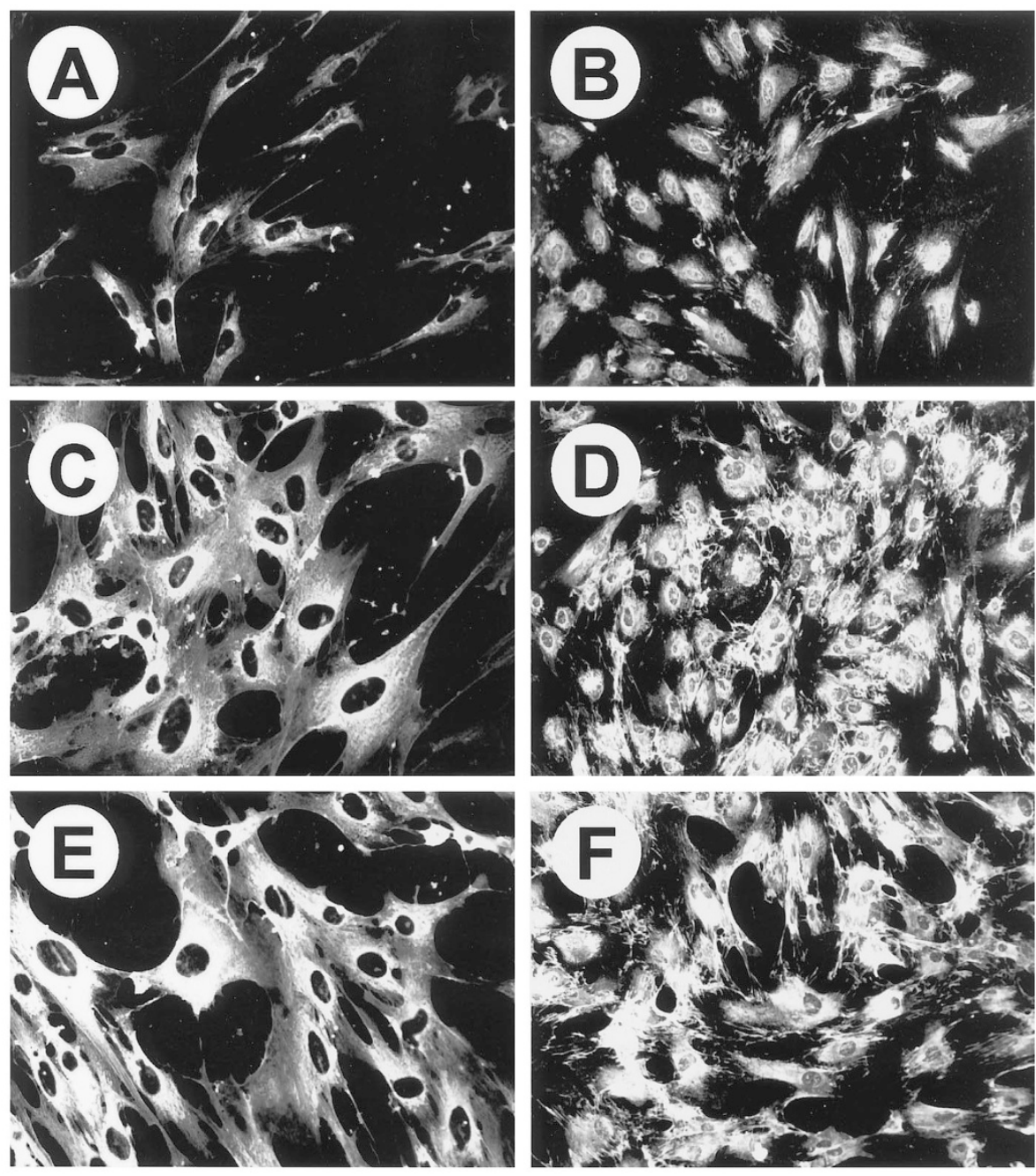

\section{Figure 4.}

Fluorescence micrographs showing the immunoreactivity of collagen type I and fibronectin in cultured human PSC stimulated with platelet lysate. Cultured human PSC ( $4^{\text {th }}$ passage) grown on glass coverslips were stimulated for 36 hours with $120 \mu \mathrm{l} / \mathrm{ml} \mathrm{nPL}$ and aPL. Thereafter cultures were washed, fixed in acetone, and immunostained. (A, C, and E) collagen type I; (B, D, and F) fibronectin; (A and B) control 0.5\% FCS; (C and D) $120 \mu \mathrm{l} / \mathrm{ml} \mathrm{nPL;} \mathrm{(E} \mathrm{and} \mathrm{F)} 120 \mu \mathrm{l} / \mathrm{ml}$ aPL. To compare staining intensities, all micrographs were taken using the same exposure time. $(\mathrm{A}, \mathrm{C}$, and $\mathrm{E})$ original magnification $\times 400$; $(\mathrm{B}, \mathrm{D}$, and $\mathrm{F})$ original magnification $\times 200$.

leading to a self-perpetuation of pancreas fibrogenesis by autocrine stimulatory loops (Bachem et al, 1999).

The central role of TGF $\beta$ in experimental and human fibrogenesis is documented by several studies (for review see Gress et al, 1998). TGF $\beta$ neutralizing antibodies injected into rats during regeneration from cerulein-pancreatitis significantly reduced collagen types I and III protein and mRNA compared with control (without anti-TGF $\beta 1$ ) (Menke et al, 1997). Furthermore, anti-TGF $\beta 1$ inhibited the rise of the steady state levels of TGF $\beta 1$ mRNA and TGF $\beta 2$ mRNA the second day after the cerulein infusion (Menke et al, 1997), suggesting that the early TGF $\beta 1$ release by platelets induces the synthesis of TGF $\beta$. In summary, the data obtained in experimental models convincingly identified TGF $\beta$ as the most prominent fibrogenic mediator in pancreas. In vivo latent TGF $\beta$ is activated predominantly by plasmin (Lyons et al, 1990). In vitro transient acidification represents the most effective procedure to activate latent $\operatorname{TGF} \beta$ (Miyazono et al,
1988). Acidified platelet lysate, containing active TGF $\beta 1$ in combination with other growth factors stored in platelets, stimulated matrix synthesis and PSC proliferation. Preincubation of the acidified platelet lysate with neutralizing antibodies to TGF $\beta 1$ and the TGF $\beta$-LAP significantly reduced cFN synthesis.

In addition, TGF $\beta$ platelets contain in their alphagranules numerous proteins, including adhesion factors, plasma proteins, coagulation factors, protease inhibitors (Davey and Luscher, 1968; Levine and Wohl, 1976; Nachman and Harpel, 1976; Koutts et al, 1978; Zucker et al, 1979; Plow and Collen, 1981), and the growth factors PDGF (Antoniades et al, 1979; Heldin et al, 1981), EGF/TGF $\alpha$ (Oka and Orth, 1983), and IGF (Karey and Sirbasku, 1989; Karey et al, 1989). All three isoforms of PDGF, the $A B$ heterodimer and the $A A$ and BB homodimers, have been isolated from human platelets. In addition to its mitogenic potency, PDGF has been shown to stimulate collagen (Butt et al, 1995) and fibronectin synthesis (Bachem et al, 1998) and to act as a potent chemoattractant for mesenchymal 


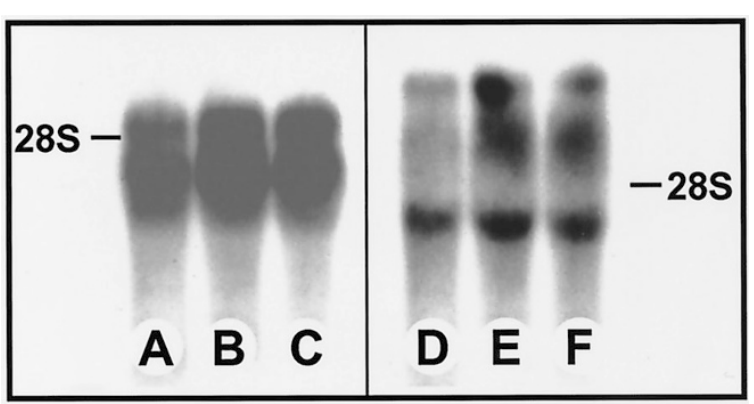

Figure 5.

Northern blot hybridization of collagen $\alpha 1(\mathrm{I})$ and fibronectin. NPL and aPL were added to secondary cultured human PSC. Cultures were stopped after 10 hours and RNA was isolated. RNA ( $30 \mu \mathrm{g} / \mathrm{lane})$ was separated by agarose gel electrophoresis and transferred to Hybond-N membranes. Ethidium bromide staining of the agarose gels was used to verify equal loading and blotting of total RNA (data not shown). Hybridizations were performed by standard procedures using $0.5 \times 10^{6} \mathrm{cpm} / \mathrm{ml}$ labeled $\mathrm{cDNA}$. Exposure to $X$-ray films was at $-70^{\circ} \mathrm{C}$ for 7 to 10 days. Lanes $\mathrm{A}, \mathrm{B}$, and $\mathrm{C}$, collagen type I; lanes $\mathrm{D}$, $\mathrm{E}$, and $\mathrm{F}$, fibronectin; lanes $\mathrm{A}$ and $\mathrm{D}$, control; lanes $\mathrm{B}$ and $\mathrm{E}, 100 \mu \mathrm{l} / \mathrm{ml} \mathrm{aPL}$; lanes $\mathrm{C}$ and $\mathrm{F}, 100 \mu \mathrm{g} / \mathrm{ml} \mathrm{nPL}$.
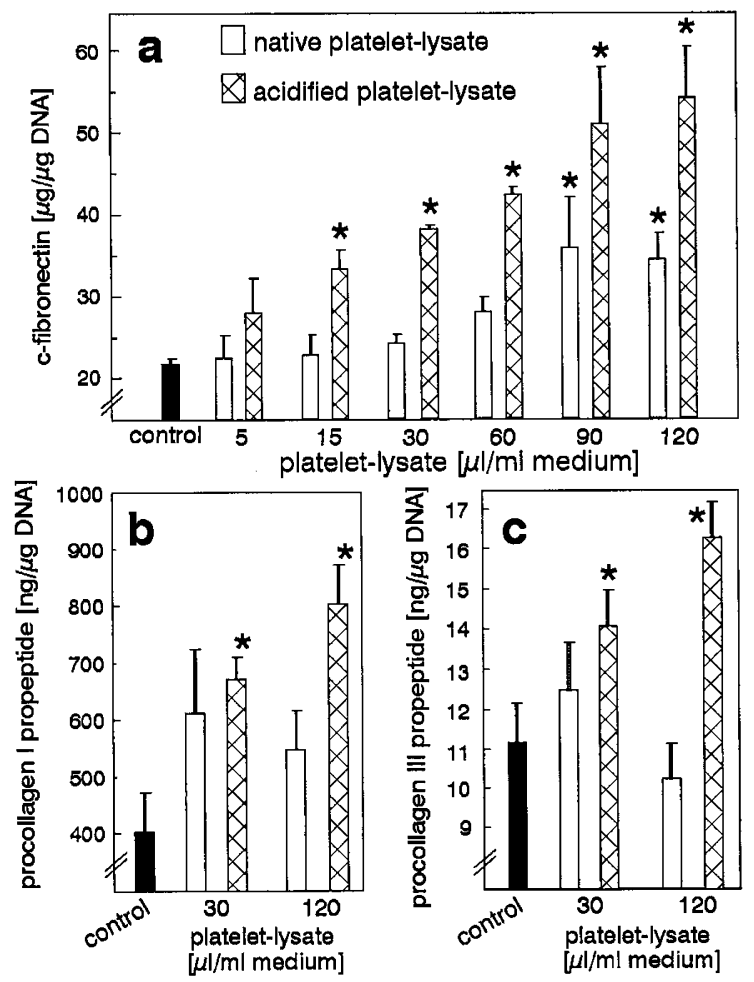

\section{Figure 6.}

Effect of platelet lysate on extracellular matrix synthesis of cultured pancreatic stellate cells. NPL and aPL were added to secondary cultured PSC grown in Dulbecco's modification of Eagle's medium with $0.5 \%$ FCS. After 48 hours cultures were stopped and fibronectin (a), procollagen I propeptide (b), and procollagen III propeptide (c) were measured in PSC supernatants; DNA was measured in the cell layer. In (a) values are expressed as means \pm SD of three independent experiments, each performed in triplicate culture wells; in (b) and (c) values are expressed as means \pm SD of two independent experiments, each performed in triplicate culture wells. ${ }^{*}$, denotes a statistically significant difference $(p<0.05)$ compared with control.

(Seppa et al, 1982) and inflammatory cells (Deuel et al, 1982). Because preincubation of the acidified platelet lysate with neutralizing antibodies to PDGF signifi- cantly reduced the mitogenic activity by $60 \%$, we conclude that PDGF is at least responsible for more than half the mitogenic activity.

TGF $\beta$ acts predominantly antiproliferatively on a variety of cell types including endothelial (Haimark et al, 1986) and pancreatic acinar cells (Logsdon et al, 1992), but also proliferative effects have been reported, for example, on osteoblasts (Centrella et al, 1987). Regarding fibroblasts and vascular smooth muscle cells, TGF $\beta$ can inhibit as well as stimulate cell growth in identical cell types (Assoian and Sporn, 1986). This bifunctional effect is probably due to the interaction with other growth factors, as proposed by Roberts et al (Roberts et al, 1985). In addition, several in vitro studies verified that $\operatorname{TGF} \beta$ stimulates cell proliferation by acting in coordination with PDGF, TGF $\alpha / E G F$, and IGFs (Assoian et al, 1984; O'Keefe et al, 1988). However, our data, which showed that preincubation of acidified platelet lysate with neutralizing antibodies to TGF $\beta 1$ and the TGF $\beta$-latency associated peptide, respectively, did not reduce the mitogenic activity, indicate that TGF $\beta 1$ is not involved in PL-induced PSC proliferation.

Modification of other growth factors by acidification may be conceivable, possibly leading to activation of a latent mitogen or destruction of a growth-inhibitory factor. IGF1 is another candidate mitogen in PL that is also complexed to binding proteins in serum. By incubation at an acidic pH, IGF might dissociate from their binding proteins. The IGF-binding proteins (IGFBP1, IGF-BP2, and IGF-BP3) regulate the half-life of IGF in the blood and modulate IGF function (for review see Rechler and Nisley, 1990).

\section{Materials and Methods}

Materials were purchased from the following sources: rabbit anti-human collagen type I and biotin labeled goat anti-human collagen type III from Chemicon International (Temecula, California); rabbit antifibronectin from Behring Diagnostics (Marburg, Germany); biotin labeled anti-rabbit, biotin labeled antimouse, HRP labeled anti-rabbit, biotin labeled anti-goat, HRP labeled anti-mouse, fluorescein-conjugated streptavidin, and HRP-conjugated streptavidin, mouse antiBrdU from Dako Diagnostika (Hamburg, Germany); streptavidin-Red 613 from Gibco BRL (Eggenstein, Germany); type I Procollagen PICP [ ${ }^{125}$ I] radioimmunoassay and type III Procollagen PIIINP [ ${ }^{125}$ I] radioimmunoassay from Orion Diagnostica (Espoo, Finland); the cDNA probes for human collagen $\alpha 1 \mathrm{I}$, collagen $\alpha 1 \mathrm{III}$, and fibronectin were from American Type Culture Collection (No. 61322, 61234, and 61038; Rockville, Maryland); mouse-anti- $\alpha$-smooth-muscle actin, BrdU, and the High Pure RNA Extraction Kit from Boehringer-Mannheim Biochemica (Mannheim, Germany); TSA Indirect from NEN Life Science Products (Boston, Massachusetts; bisbenzimide, calf thymus DNA, yeast t-RNA, diethylendtriaminepentaacetic (DTPA), monoclonal antifibronectin, and $\beta$-aminopropionitrile from Sigma Chemie (Deisenhofen, Germany); ascorbic acid (Merck, Darmstadt, Germany); enhancement solution and 

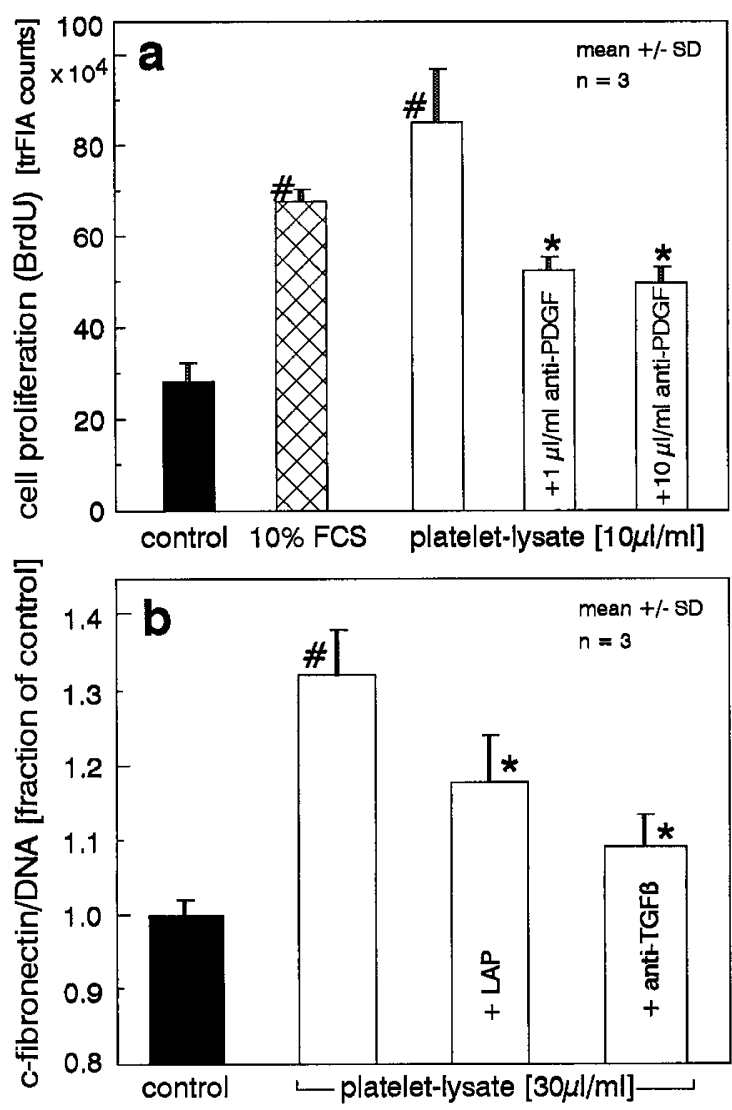

Figure 7.

Identification of PDGF as the responsible mitogen and TGF $\beta 1$ as the matrixsynthesis-stimulating activity of platelet lysate. (a) Effect of anti-PDGF on platelet lysate-induced proliferation of cultured PSC. aPL was preincubated for 30 minutes with neutralizing anti-PDGF $(1 \mu \mathrm{l} / \mathrm{ml}$ and $10 \mu \mathrm{l} / \mathrm{ml})$ before lysates were added to secondary cultured PSC grown in Dulbecco's modification of Eagle's medium with $0.5 \%$ FCS. Four hours after addition of platelet lysates (10 $\mu \mathrm{l} / \mathrm{ml}$ medium), BrdU (final concentration $10^{-5} \mathrm{M}$ ) was added. Cultures were stopped 16 hours later. BrdU incorporation was measured quantitatively as described in the Methods section. Values are expressed as means \pm SD of one representative experiment, each performed in triplicate culture wells. \#, denotes a statistically significant $(p<0.05)$ difference to control; * , denotes a significant $(p<0.05)$ difference to platelet lysate without anti-PDGF. (b) Effect of anti-TGF $\beta 1$ and TGF $\beta 1$-LAP platelet lysate-induced cFN synthesis of cultured PSC. aPL was preincubated for 30 minutes with neutralizing anti$\operatorname{TGF} \beta 1(1 \mu \mathrm{l} / \mathrm{ml}$ and $10 \mu \mathrm{l} / \mathrm{ml})$ before lysates were added to secondary cultured PSC grown in Dulbecco's modification of Eagle's medium with $0.5 \%$ FCS. After 24 hours cultures were stopped and cFN was measured in PSC supernatants; DNA was measured in the cell layer. Values are expressed as means \pm SD of one representative experiment, each performed in triplicate culture wells. \#, denotes a statistically significant $(p<0.05)$ difference compared with control; ${ }^{*}$, denotes a significant $(p<0.05)$ difference to platelet lysate without preincubation with LAP and anti-TGF $\beta 1$.

europium-conjugated streptavidin from Wallac Oy (Turku, Finland); and neutralizing anti-human TGF $\beta 1$, TGF $\beta$-latency-associated peptide, and neutralizing anti PDGF from R and D Systems (Minneapolis, Minnesota). The 18S rRNA probe was generously provided by Dr. T.M. Gress (University Ulm, Germany). The 96-well microtiter-plates (Maxi Sorp) were from Nunc $\mathrm{GmbH}$ (Wiesbaden, Germany), and cell culture plates and flasks were from Falcon (Becton Dickinson, Heidelberg, Germany). Hybond-N membranes were purchased from Amersham-Buchler (Braunschweig, Germany).

\section{Preparation of the Platelet Lysate}

Frozen outdated human platelet concentrates (obtained from the Blutspendezentrale of the German Red Cross in Ulm, Germany) were thawed, lysed by sonification, and centrifuged at $4^{\circ} \mathrm{C}$ for 20 minutes at $3000 \times g$. Thereafter, clotting cascade was initialized by addition of $\mathrm{CaCl}_{2}(15 \mathrm{mmol} / \mathrm{l})$ to the supernatant. Fibrin clots were removed and the supernatant was dialyzed extensively (cut-off Mr 3500) against Dulbeccos modification of Eagle's medium at $4^{\circ} \mathrm{C}(3 \times 12$ hours, 100-fold volume). One aliquot was transiently acidified with $1 \mathrm{~N} \mathrm{HCl}(\mathrm{pH} 2,30$ minutes) and thereafter neutralized using $1 \mathrm{~N} \mathrm{NaOH}$. Native (nPL) and the transiently acidified platelet lysate (aPL) were sterilized by passing through a $0.2-\mu \mathrm{m}$ filter and added to cell cultures immediately.

\section{Isolation and Culture of Pancreatic Stellate Cells}

Human pancreatic stellate cells were isolated and cultured as described previously (Bachem et al, 1998). Cells were cultured in DMEM/Ham's F12, (1:1, v/v) with antibiotics and $10 \%$ fetal calf serum. All experiments were performed using passaged cells (3rd to 7 th passage). The purity of the cultures was assessed by phase-contrast microscopy and positive staining of vimentin and $\alpha$-smooth muscle actin.

To measure cFN- and collagen-synthesis in cell culture supernatants, PSC were grown in 24-well plates. $\mathrm{L}(+)$ ascorbic acid $(100 \mu \mathrm{g} / \mathrm{ml})$ and $\beta$-aminopropionitrile $(64 \mu \mathrm{g} / \mathrm{ml})$ were added to inhibit collagen crosslinking and to increase proline hydroxylation and collagen secretion. To perform immunofluorescence microscopy, cells were grown on glass coverslips in 6-well plates (10 $\mathrm{cm}^{2} /$ well). To isolate mRNA, cells were grown in flasks $\left(75 \mathrm{~cm}^{2}\right)$. During stimulation with PL, fetal calf serum was reduced to $0.5 \%$. Cell culture supernatants were removed 48 hours after addition of $\mathrm{PL}$ and stored at $-80^{\circ} \mathrm{C}$ until quantitative measurement of $\mathrm{cFN}$, collagen type I, and procollagen I peptide (PICP).

\section{Determination of Extracellular Matrix Synthesis}

cFN was measured by time resolved fluorescence immunoassay as described (Bachem et al, 1998, 1999). All measurements (standards, controls, and samples) were obtained in duplicate. Variation in the duplicate measurements was usually between $0.5 \%$ and $5 \%$, and did not exceed $8 \%$.

Procollagen-I peptide and procollagen III peptide were measured using commercially available radioimmunoassays according the manufacturers instructions. All measurements were made in duplicate.

\section{Immunofluorescence Microscopy of Collagen Type I and Fibronectin}

Glass coverslips with cultured hPSC were washed in PBS to remove medium proteins, fixed for 30 minutes in $-20^{\circ} \mathrm{C}$ acetone, and blocked with TNB $(0.1 \mathrm{M}$ Tris- $\mathrm{HCl}, 0.15 \mathrm{M} \mathrm{NaCl}, 0.5 \% \mathrm{RIA}$ grade albumin, $\mathrm{pH}$ 7.4) for 45 minutes. For collagen type I, the staining 
sequence was rabbit-anti-human-collagen I (1:50), biotin-anti-rabbit (1:100), streptavidin-HRP (1:100), biotin-TSA-reagent (1:40), and streptavidin-FITC $(1: 100)$. The staining sequence for fibronectin was primary antibody (rabbit-anti-fibronectin, 1:50), secondary antibody (biotin-anti-rabbit, 1:100), and streptavidin-FITC (1:100). For $\alpha$-smooth muscle actin, the staining sequence was primary antibody (mouse anti- $\alpha$-smooth muscle actin, 1:50), secondary antibody (HRP-anti-mouse, 1:50), biotin-TSA-reagent (1:40), and streptavidin-FITC (1:100). Each incubation step was followed by rinsing ( $3 \times 5$ minutes with PBS). Staining was observed using epifluorescence microscopy (Carl Zeiss, Oberkochen, Germany) and photographs were taken using Ektachrome 400 film (Kodak). To compare different staining intensities, exposure time was always the same. Nonspecific staining was controlled by including rabbit- or mouse-non-immune serum instead of specific primary antibody.

\section{Electron Microscopy}

Pancreatic tissue was surgically resected from 10 patients with acute pancreatitis. The tissue was fixed for 1 hour in a mixture of $2.5 \%$ glutaraldehyde and $2.5 \%$ formaldehyde, in a cacodylate buffer. Standard procedures were used for dehydration and embedding. Ultrathin sections were stained with uranyl acetate and lead citrate, and examined using a transmission electron microscope (Zeiss EM 10).

\section{Determination of Cell Proliferation}

BrdU-incorporation was quantified by time-resolved fluorescence of a europium-chelate (Bachem et al, 1995). Briefly, cells were labeled for 16 hours with BrdU $\left(5 \times 10^{-5} \mathrm{M}\right)$. Thereafter, cell cultures were washed twice with TNT (TNT: $0.1 \mathrm{M}$ Tris- $\mathrm{HCl}, 0.15 \mathrm{M}$ $\mathrm{NaCl}, 0.05 \%$ Tween 20, $\mathrm{pH} 7.4$ ), fixed using ethanol/ acetic acid $(95 / 5, \mathrm{v} / \mathrm{v})$, and thereafter incubated for 20 minutes at $4^{\circ} \mathrm{C}$ with $0.05 \mathrm{M} \mathrm{HCl}$. After another washing step, DNA was cleaved by incubation for 45 minutes at $80^{\circ} \mathrm{C}$ with formamide/trisodium-citrate $(88 \mathrm{mg}$ trisodium-citrate in $38 \mathrm{ml}$ formamide). After 2 washing steps, non-specific binding was blocked by incubation with serum (diluted 1:1 with TNT buffer) followed by 3 washing steps. Thereafter, primary antibody (mouseanti-BrdU IgG diluted 1:500 in TNB) was added and incubated with gentle shaking for 2 hours at $22^{\circ} \mathrm{C}$. After 3 further washing steps, secondary antibody (biotin-labeled anti-mouse IgG, diluted 1:500 in TNB) was added and incubated for another 60 minutes; thereafter DTPA (Diethylentriaminepantaacetic acid, $20 \mu \mathrm{mol}$ in TNB, $\mathrm{pH}$ 7.4) was added and incubated for 15 minutes at room temperature. After 3 additional washing steps europium-labeled Streptavidin (diluted in TNB 1:1000) was added and incubated for 1 hour. After 5 washing steps, enhancement solution (150 $\mu \mathrm{l} /$ well) was added, and incubated for 45 minutes at $22^{\circ} \mathrm{C}$. Finally time-resolved fluorescence of the europium-chelate was counted in a $100-\mu$ l aliquot using a Delfia Victor 1420 Multilabel Counter (Wallac Oy).

BrdU incorporation was also visualized by immunostaining. Briefly, cells were cultured in 6-well plates, stimulated, and fixed after labeling with BrdU as described above. The first steps in the staining procedure were performed in the same way as described for quantitative BrdU determination. The secondary antibody was HRP-conjugated rabbit-anti-mouse IgG (diluted 1:100 in TNB). After incubation for 120 minutes with the secondary antibody followed by 3 washing steps, the nuclei that had incorporated BrdU were stained using 3,3'-diaminobenzidine tetrahydrochloride as substrate and hydrogen peroxide $0.3 \%$ with nickel- and cobalt-chloride as intensifier. DNA was quantified as previously described (Labarca and Paigen, 1980) by fluorometry using bisbenzimide and calf thymus DNA as a standard.

\section{RNA Isolation and Northern Blot}

PSC cultures were stopped 10 hours after stimulation with PL to extract total RNA using the High Pure RNA Isolation Kit. For Northern blot analysis, $30 \mu \mathrm{g}$ of total RNA was separated by gel electrophoresis in $1 \%$ agarose and $2.2 \mathrm{~mol} / \mathrm{l}$ formaldehyde and transferred by capillary elution to Hybond-N membranes. Ethidium bromide staining of the agarose gels and hybridization with an $18 \mathrm{~S}$ ribosomal RNA probe were used to verify equal loading and blotting of total RNA. Purified cDNA probes were labeled with [32P]dCTP. Prehybridizations (4 to 6 hours) and hybridizations (14 hours) were carried out in $6 \times$ standard saline citrate ( 1 $x$ SSC $=150 \mathrm{~mm} \mathrm{NaCl}, 15 \mathrm{~mm}$ sodium citrate), $5 \times$ Denhardt's reagent, $0.5 \%$ sodium dodecyl sulfate (SDS), $100 \mu \mathrm{g} / \mathrm{ml}$ yeast t-RNA, $50 \mu \mathrm{g} / \mathrm{ml}$ sonicated human placenta DNA, $10 \mu \mathrm{g} / \mathrm{ml}$ polyU-homopolymer, and $50 \%$ formamide at $42^{\circ} \mathrm{C}$. The hybridization buffer was supplemented with $0.5 \times 10^{6} \mathrm{cpm} / \mathrm{ml}$ labeled cDNA. The membranes were washed several times with decreasing concentrations of SSC $+0.1 \%$ SDS, the final high-stringency wash was done in $0.2 \times$ SSC. Exposure to X-ray films was done at $-70^{\circ} \mathrm{C}$ for 7 to 10 days.

\section{Statistical Analysis}

All quantitative measurements were obtained in duplicate. For quantitative measurement of cFN, DNA, and BrdU incorporation, results are presented as means \pm SD of three independent experiments, each condition performed with 3 cultures. Procollagen-I-peptide and procollagen-III-peptide results are presented as means \pm SD of two independent experiments $(n=6)$. An ANOVA-test was employed to compare different groups.

\section{Conclusion}

We concluded that factors released from platelets stimulate cell growth and the synthesis of extracellular matrix in cultured human PSC. In this complex pattern of growth factors and other bioactive peptides, TGF $\beta 1$ 
seems to represent the major matrix synthesis stimulating activity and PDGF the most responsible mitogen. Our results confirm the hypothesis that platelets, aggregating in injured sites of the pancreas, release growth factors that initiate and propagate fibrosis in chronic pancreatitis.

\section{References}

Antoniades HN, Scher CD, and Stiles CD (1979). Purification of human platelet-derived growth factor. Proc Natl Acad Sci USA 76:1809-1813.

Apte MV, Haber PS, Applegate TL, Norton ID, McCaughan GW, Korsten MA, Pirola RC, and Wilson JS (1998). Periacinar stellate shaped cells in rat pancreas: Identification, isolation, and culture. Gut 43:128-133.

Assoian RK and Sporn MB (1986). Type $\beta$ transforming growth factor in human platelets: release during platelet degranulation and action on vascular smooth muscle cells. J Cell Biol 102:1217-1223.

Assoian RK, Grotendorst GR, Miller DM, and Sporn MB (1984). Cellular transformation by coordinated action of three peptide growth factors from human platelets. Nature 309: 804-806.

Assoian RK, Komoriya A, Meyers CA, Miller DM, and Sporn MB (1983). Transforming growth factor-beta in human platelets. Identification of a major storage site, purification and characterization. J Biol Chem 258:7155-7160.

Bachem MG, Dietz R, and Gressner AM (1995). Quantitative measurement of cell proliferation using incorporation of 5-bromo-2-deoxyuridine, monoclonal antibody against 5-bromo-2-deoxyuridine (Mab anti-BrdUrd) and timeresolved fluorometry of europium chelat (Abstract). Eur J Clin Chem Clin Biochem 33:A30.

Bachem MG, Kandenwein J, Kadlec N, Schmid-Kotsas A, Menke $A$ et al (1999). Transforming growth factor $\beta 1$ is involved in autocrine stimulated matrix synthesis of pancreatic stellate cells (Abstract). Clin Chem Lab Med 37:S118.

Bachem MG, Schneider E, Gro $\beta$ H, Weidenbach H, Schmid RM, Menke A, Siech M, Berger H, Grunert A, and Adler G (1998). Identification, culture and characerization of pancreatic stellate cells in rats and humans. Gastroenterology 115:421-432.

Bockman DE (1988). Early association of duodenal contents and blood with acini during experimental pancreatitis. Int $\mathrm{J}$ Pancreatol 3:333-342.

Bockman DE, Buchler M, Beger HG (1986). Ultrastructure of human acute pancreatitis. Int J Pancreatol 1:141-153.

Butt RP, Laurent GJ, and Bishop JE (1995). Collagen production and replication by cardiac fibroblasts is enhanced in response to diverse classes of growth factors. Eur $\mathrm{J}$ Cell Biol 68:330-335.

Centrella M, McCarthy TL, and Canalis E (1987). Transforming growth factor-beta is a bifunctional regulator of replication and collagen synthesis in osteoblast enriched cell cultures from fetal rat bone. J Biol Chem 262:2869-2874.

Davey MG and Luscher EF (1968). Release reactions of human platelets induced by thrombin and other agents. Biophys Acta 165:490-506.
Deuel TE, Senior RM, Huong JS, and Griffin GL (1982). Chemotaxis of monocytes and neutrophils to platelet-derived growth factor. J Clin Invest 69:1046-1049.

Di Magno EP, Layer P, and Clain JE (1993). Chronic pancreatitis. In: Go VWL, Di Magno EP, and Gardner JD, editors. The pancreas, 21 ed. New York: Raven Press, 655-706.

Elsässer HP, Adler G, and Kern HF (1986). Time course and cellular source of pancreatic regeneration following acute pancreatitis. Pancreas 1:421-429.

Elsässer HP, Adler G, and Kern HF (1989). Fibroblast sructure and function during regeneration from hormone-induced acute pancreatitis in the rat. Pancreas 4:169-178.

Gress TM, Menke A, Bachem M, Müller-Pillasch F, Ellenrieder V,Weidenbach $\mathrm{H}$, Wagner $\mathrm{M}$, and Adler $\mathrm{G}$ (1998). Role of extracellular matrix in pancreatic diseases. Digestion 59: $625-637$.

Gress M, Müller-Pilasch F, Elsässer HP, Bachem M, Ferrara C, Weidenbach H, Lerch M, and Adler G (1994). Enhancement of transforming growth factor $\beta 1$ expression in the rat pancreas during regeneration from caerulein-induced pancreatitis. Eur J Clin Invest 24:679-685.

Haimark RL, Twardzik DR, and Schwartz SM (1986). Inhibition of endothelial regeneration by type-beta transforming growth factor from platelets. Science 233:1078-1080.

Heldin CH, Westermark B, and Wasteson A (1981). Plateletderived growth factor. Isolation by a large-scale procedure and analysis of subunit composition. Biochem J 193:907913.

Karey KP and Sirbasku DA (1989). Human platelet-derived mitogens. II. Subcellular localization of insulinlike growth factors $I$ to the alpha-granule and release in response to thrombin. Blood 74:1093-1100.

Karey KP, Marquardt H, and Sirbasku DA (1989). Human platelet-derived mitogens. I. Identification of insulinlike growth factors I and II by purification and $\mathrm{N}$ alpha amino acid sequence analysis. Blood 74:1084-1092.

Kato Y, Inoue H, Fujiyama Y, and Bamba T (1996). Morphological identification and collagen synthesis of periacinar fibroblastoid cells isolated and cultured from rat pancreatic acini. J Gastroenterol 31:565-571.

Kennedy RH, Bockmann DE, Uscanga L, Choux R, Grimaud JA, and Sarles H (1987). Pancreatic extracellular matrix alterations in chronic pancreatitis. Pancreas 2:61-72.

Koutts J, Walsh PN, Plow EF, Fenton JW, Bouma BN, and Zimmerman TS (1978). Active release of human platelet factor VIII-related antigen by adenosine diphosphate, collagen and thrombin. J Clin Invest 62:1255-1263.

Labarca C and Paigen K (1980). A simple, rapid and sensitive DNA assay procedure. Anal Biochem 102:344-352.

Levine SP and Wohl H (1976). Human platelet factor 4: Purification and characterization by affinity chromatography: Purification of human platelet factor 4. J Biol Chem 251:324328.

Logsdon CD, Keyes L, and Beauchamp D (1992). Transforming growth factor-beta (TGF $\beta 1$ ) inhibits pancreatic acinar cell growth. Am J Physiol 262:364-368.

Lyons RM, Gentry LE, Purchio AF, and Moses HL (1990). Mechanism of activation of latent recombinant transforming growth factor beta 1 by plasmin. J Cell Biol 110:1361-1367. 
Menke A, Yamaguchi H, Gress TM, and Adler G (1997). Extracellular matrix is reduced by inhibition of transforming growth factor- $\beta 1$ in pancreatitis in the rat. Gastroenterology 113:295-303.

Miyazono K, Hellman U, Wernstedt C, and Heldin CH (1988). Latent high molecular weight complex of transforming growth factor $\beta 1$. J Biol Chem 263:6407-6415.

Nachman RL and Harpel PC (1976). Platelet alpha2macroglobulin and alpha1-antitrypsin. J Biol Chem 251: 4514-4520.

Oka Y and Orth DN (1983). Human plasma epidermal growth factor/beta-urogastrone is associated with blood platelets. $\mathrm{J}$ Clin Invest 72:249-259.

O'Keefe RJ, Puzas JE, Brand JS, and Rosier RN (1988). Effect of transforming growth factor-beta on DNA synthesis by growth plate chondrocytes: Modulation by factors present in serum. Calcif Tissue Int 43:352-358.

Plow EF and Collen D (1981). The presence and release of alpha 2-antiplasmin from human platelets. Blood 58:10691074.

Rechler MM and Nisley SP (1990). Insulin-like growth factors. In: Sporn MB and Roberts A, editors. Peptide growth factors and their receptors: Handbook of experimental pharmacology. Berlin, Heidelberg, New York: Springer, 95/l:263-346.
Roberts AB, Anzano MA, Wakefield LM, Roche NS, Stern DF, and Sporn MB (1985). Type $\beta$ transforming growth factor: A bifunctional regulator of cellular growth. Proc Natl Acad Sci USA 82:19-123.

Saotome T, Inoue H, Fujimiya M, Fujiyama Y, and Bamba T (1997). Morphological and immunocytochemical identification of periacinar fibroblast-like cells derived from human pancreatic acini. Pancreas 14:373-382.

Sarles H, Bernard JP, and Gullo L (1990). Pathogenesis of chronic pancreatitis. Gut 31:629-632.

Seppa H, Grotendorst G, Seppa S, Schiffman E, and Martin $G$ (1982). Platelet-derived growth factor is chemotactic for fibroblasts. J Cell Biol 92:584-588.

Uscanga L, Kennedy RH, Choux R, Druguet M, Grimaud JA, and Sarles $H$ (1987). Sequential connective matrix changes in experimental acute pancreatitis: An immunohistochemical and biochemical assessment in rat. Int J Pancreatol 2:33-45.

Zucker MB, Mosesson MW, Broekman MJ, and Kaplan KL (1979). Release of fibronectin (cold-insoluble globulin) from alpha-granules induced by thrombin or collagen; lack of requirement for plasma fibronectin in ADP-induced platelet aggregation. Blood 54:8-12. 